\title{
STUDY OF SCRAP WASTE IN KATHMANDU VALLEY
}

\author{
Kishor P. Luitel*, Sanjay Nath Khanal \\ Department of Environmental Science and Engineering, \\ Kathmandu University, P.O. Box 6250, Nepal. \\ *Corresponding author: kishorluitel@gmail.com \\ Received 20 September, 2009; Revised 25 January, 2010
}

\begin{abstract}
Scrap wastes are the wastes which are the part of the solid waste, segregated and taken further for reusing and recycling from the mixed waste. This scrap waste is called the Kabadi Waste in Nepal. The objective of this study is to identify the scrap waste material and assess collection and business activity of scrap waste generated with in Kathmandu Valley. Direct observations, formal and informal discussion, field study with questionnaire were used for data acquisition. 33 random samples, out of 178 scrap shop were selected for study. During the period of this study waste from transfer station was not allowed to collect by outsiders except by the employed person of the municipality. The composition of scrap waste consisted of $32.49 \%$ glasses, $23.89 \%$ papers, $22.65 \%$ plastics and others (metals, textile, leather and rubber) $20.97 \%$. Among those reusable material consisted of $38.96 \%$ and $44.77 \%$ was recyclable materials; remaining could be either recycled or reused. $41 \%$ of scrap waste collection was done through door to door by cycle hawker. 53\% of the scrap waste was found recycled or reuse in Nepal. Similarly, $45 \%$ of scrap dealers processed scrap for further recycling. 36\% of the Kabadi shop has employed less than 10 people for the waste collection. Now, people from lower casts were also found involved in this business. This study clearly indicates the significance of scrap waste which is a part of Municipal Solid Waste.
\end{abstract}

Keywords: Solid Waste, Recycle, Reuse, Trade of Secondary Material, Scrap, Kabadi.

\section{INTRODUCTION}

Due to urbanization, environmental sanitation, including solid waste management has become a critical issue (Devkota et al. 2004). In Asia, all kind of waste generated are collected and treated by municipalities (UNEP/ GRID-Arendal, 2006). Waste disposal in developing countries is still largely uncontrolled, and vast quantities of waste remain uncollected (Blight and Mbande, 1998). Waste composition differs from developing countries with high proportion of organic waste to developed countries having large fraction of paper and plastic (Dhussa and Varsney, 2000). Currently, developing countries are experiencing a similar trend in urbanisation and industrialisation which as become the main cause of increased generations of solid wastes (AIT, 2004).

Waste is waste until the recycling and recovered value is more than the cost and labour for recovery. (Neogi, 2000) Recycling means some additional labor, energy and technology. The term "Recycling" has two dimensions - recovery and utilization (Pier, 1998). Recovery refers to the diversion and collection of waste materials from landfills, incinerators, or other disposal methods. Utilization refers to the processing of diverted waste into new and useful materials and products. Scrap wastes are the 
wastes which are the part of the solid waste, segregated and taken further for reusing and recycling from the mixed waste. Locally in Kathmandu it is called Kabadi Waste. Waste recycling will help reduce the use of raw materials and gain the maximum value of the waste materials (Conitreau et al. 1984; Beed and Bloom, 1995; EPA, 1996; WBCSD, 2004). Recycling is also a means of job creation and generation of income, especially among low-income groups (Muller, 2002). In Asia Pacific region, waste recycling increased from 10\% to 22\% within 1990 to 1998 (UN, 2000).

The objective of this study is to identify the scrap waste material and assess its collection and business activity with in Kathmandu valley. The Current trend of waste generation in Kathmandu Valley is increasing, in which the waste having high scrap value is growing due to changing lifestyle of the people. This research study focus on the solid waste generated in the Kathmandu Valley and the waste taken for the reuse and recycling as a Kabadi waste. This research in many ways may help in the management of the waste as it makes the classification and separation of the waste easier, making the further disposal practices safer, and environmentally friendly. This study is an attempt to provide up to date compilation of the information about Kabadi waste management system in Kathmandu Valley.

\section{STUDY AREA \& METHODOLOGY}

The study covered the jurisdiction of the five municipalities in the Kathmandu Valley, namely Katmandu Metropolitan City (KMC), Lalitpur Sub Metropolitan City (LSMC), Bhaktapur Municipality (BKM), Madhyapur Thimi Municipality (MTM) and Kirtipur Municipality (KRM). The study was done only for the materials that are collected by the Kabadi waste dealers. In one month duration random sampling was done in 33 Kabadi dealers in 5 Municipalities of Kathmandu Valley from among 178 officially known. The field study comprised questionnaire survey, formal and informal discussion with Kabadi dealers and other stakeholders.

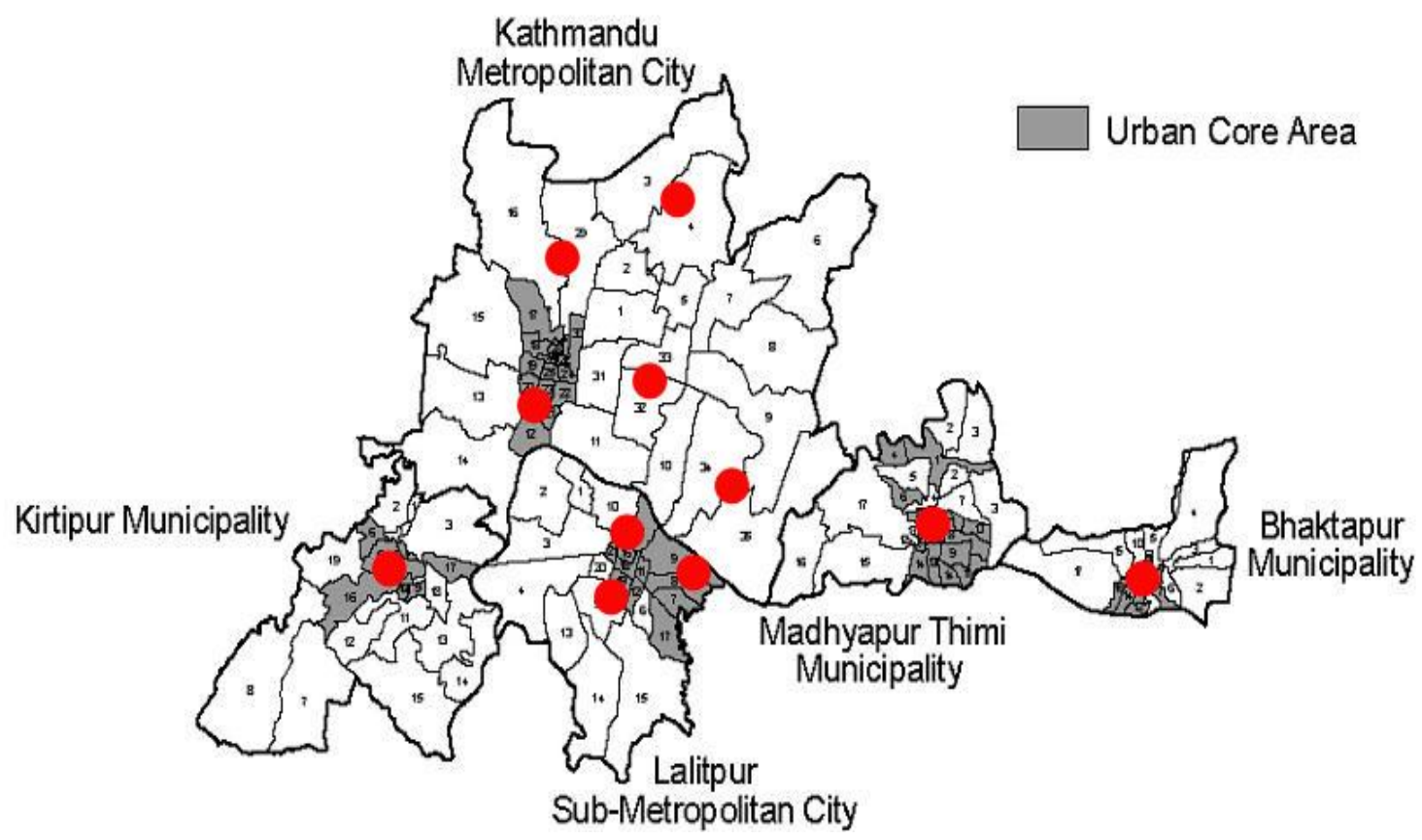


Figure 1: Study area with sampling site in Kathmandu Valley. Nepal (Source: Nippon Koie, 2005).

Each dot indicates 3 sampling site.

Preliminary Survey was conducted in different places for sample site selection of Kabadi shops in Kathmandu Valley. Consultation with the expert related to Solid Waste Management about the situation of the reuse and recycling of the waste in Kathmandu Valley was also done. From the structured questionnaire, the method of the collection of different material, existing system of the scrap waste business, categorization of the waste collected by the Kabadi dealers, flow of the waste from the household to the Kabadi dealers, overall scenario of the scrap waste collection and utilization of the waste for recycling and reusing of the waste. Questionnaire of this study is on the annex II.

Waste which is produced in houses, industries and other business places are collected through various methods; for example door to door collection, auctions, transfer station, Kabadi dealers. From these data, scrap waste production place, collection network were determined to indentify the flow of the scrap waste within Katmandu Valley from household to the Kabadi dealer. Further transaction and end point of the scrap waste for reuse and recycling to industries and houses was recognized. A general scenario of number of people involved in a Kabadi station and which region people are from in scrap waste business are studied. Items regarded as recyclable and reusable materials are listed on annex I.

\section{RESULTS AND DISCUSSION}

\section{Composition of the Scrap Waste}

From the field study, Glass has the highest amount with $32.49 \%$ followed by paper $23.89 \%$, plastic $22.65 \%$, metals $18.4 \%$ and other. Proportion of Recyclable material is high than the Reusable.

Table 1: Composition of Scrap Waste in Kathmandu Valley (Source: Field Study 2008)

\begin{tabular}{lc}
\hline Composition & Percentage \\
\hline Glass & 32.49 \\
Plastic & 22.65 \\
Textile, Rubber and leather & 2.58 \\
Metals & 18.4 \\
Paper & 23.89 \\
\hline Total & $\mathbf{1 0 0}$ \\
\hline Reusable & $\mathbf{3 8 . 9 6}$ \\
\hline Recyclable & $\mathbf{4 4 . 7 7}$ \\
\hline Reusable and recyclable & $\mathbf{1 6 . 2 7}$ \\
\hline
\end{tabular}




\section{Scrap Waste Collection Methods}

Several waste materials are collected by itinerant traders in Kathmandu. After sorting and cleaning, these materials are exported to the neighboring country, India, where these materials are recycled (Beukering \& Badrinath 1995).

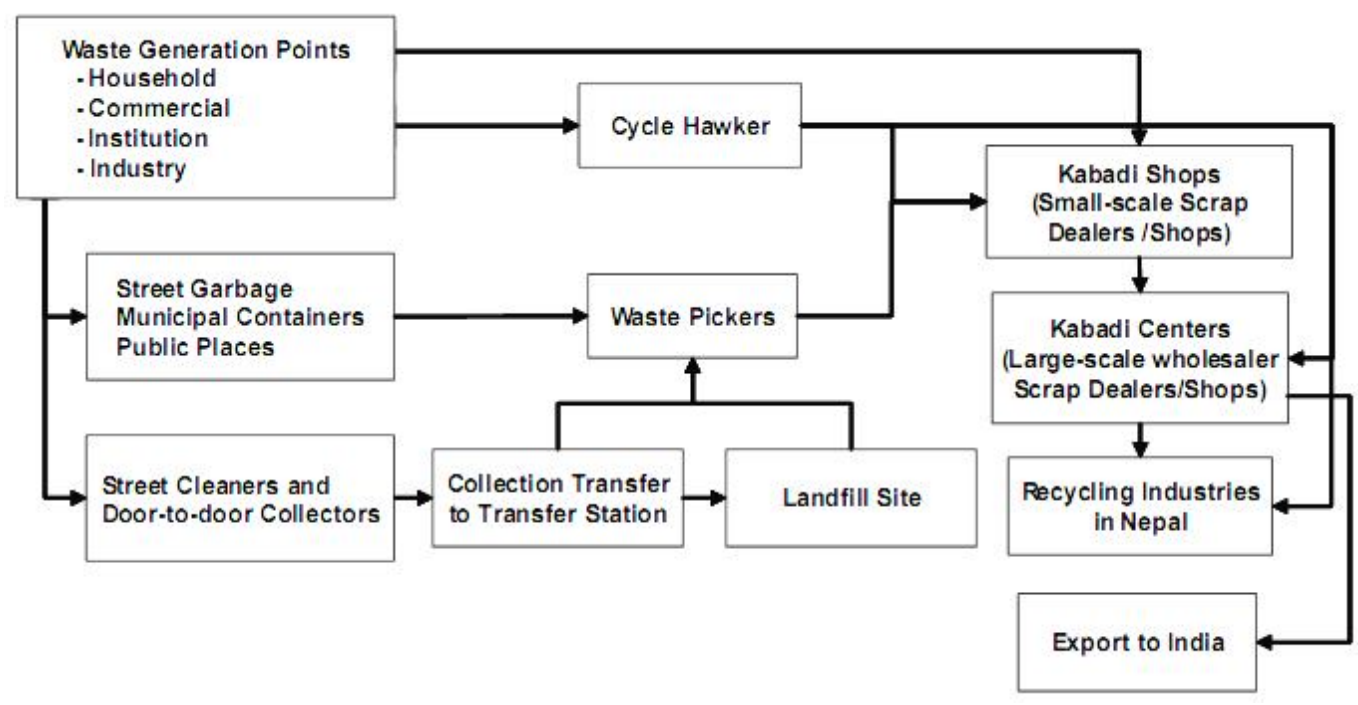

Figure 2: Scrap Waste flow in Kathmandu Valley. Nepal (Source: Nippon Koie, 2005)

From this field study, Most of the scrap waste was found collected by door to door collection system, which consists of $41 \%$. The cycle hawker collects the waste from door to door. Especially they collect paper, iron, glass bottle and sack. From street the "Khate" (Scavengers) collect 12\% of the waste consists of plastic iron, paper etc. Industries call for auction of the waste collected to the Kabadi shop in large quantity which consists of $29 \%$. It also consists of the waste collected from the construction and demolition site. These specially consist of iron and Bottles. During the period of this study waste from transfer station was not allowed to collect by outsiders except by the employed person of the municipality. So it does not contribute for the scrap waste collected from the transfer station directly in this study. Waste collection from the transfer station has stopped since almost one year. Among the scrap dealer $6 \%$ sell to large Kabadi shop or Kabadi center, Most of them export directly.

Table 2: Scrap Waste Collection Methods in Kathmandu Valley, Nepal (Source: Field Study 2008)

\begin{tabular}{lr}
\hline Places of collection & Percentage \\
\hline Door to door & 41.18 \\
Street & 11.76 \\
Transfer station & 0.00 \\
Auction & 29.41 \\
Kabadi & 5.88 \\
Others & 11.76 \\
\hline Total & 100 \\
\hline
\end{tabular}




\section{Selling Methods of Scrap Waste Collected}

Industries or large Kabadi units, who need the scrap waste, come to these Kabadi shops to buy the material they require. $77 \%$ of wastes are bought from the Kabadi shop. The Kabadi shop does not have to go for marketing of the scrap material. Only $23 \%$ of the materials are sold by Kabadi shops to different Kabadi centers and industries.

\section{Business Places for Scrap Waste}

This study showed that $53 \%$ of the scrap wastes are recycled or reused in Nepal. It consists of iron and paper for recycling and bottle and sack for reuse. $21 \%$ of wastes are sold in Kabadi shop from small shop to big shop. Only 5\% is send to India, which consists of plastic, glasses and tin. $21 \%$ are sold to the local people in small amount, mostly iron and other reusable thing in home. Other waste may be send to industries in India as well as in Nepal. Lead, glass pieces and textile are all exported to India. Metals, paper, burned mobile, tyre tube, plastics are used in Nepal or exported to India. Reusable sacks of jute, plastic and empty bottles are all utilized in Nepal. 116 tones of the recyclable materials, which make $84 \%$ of the total, are exported from the Valley. Among them $16 \%$ of collected recyclable materials are recycled within the Valley (Nippon Koie, 2005).

Presently industries in Nepal are not only using the waste generated here but also importing. Bhrikuti paper industry imports paper from Singapore, Everest paper industry, Ashok and Jagadamba steel industries also import raw materials. Papers are used by Webko, Jamarko, Bhrikuti, Everest and MK paper industries. Irons are used by Ashok, Jagadamba and Panchakanya steel industries. They are also exported to India. Beer, medicinal, cold drinks and alcohol bottles are send to their respective factory. Plastics, Burned mobile and tyre tubes are used in Nepal as well as exported to India. Plastic bottles are shredded into pellets and send to the industries in India. Tyres are used as the fuel for combustion by different industries; construction of road as well as it is used as a tool for protest on streets. Burned mobile are used by vehicles after sedimentation and also as fuel for combustion. Natural and artificial wool threads, pieces garment cloth, jute and plastic sack, lead and glass pieces are exported to India.

\section{Processing of Scrap Waste in Kabadi Shop}

Under waste processing, the material collected first goes for segregation. Iron are made straight, plastic bottle are cut to pieces. Glass bottles are cleaned. Shoes Sole are separated. $45 \%$ of the Kabadi shop does waste processing activity. $55 \%$ of the Kabadi shop does not process the waste they only collect. Plastic bottles are cut into pieces to reduce its volume. After cleaning glass bottles they are sold to their respective industries and shoes sole are sold to the shoes industries of Nepal. Reusable irons are reused after straightening.

\section{Employment in the Kabadi Shop}

Cycle hawkers are the people who are earning their living from selling the material they collect. They are the first step for waste minimization process. They stay in the Kabadi shop and sell their collection to the Kabadi shop. Their income depends upon the amount of material they collect. $36 \%$ of Kabadi shop has employed less than 10 people, $18 \%$ has employed more than 10 people, like that $37 \%$ has employed less than 5 people and $9 \%$ has not employed any other person. 
It has been estimated that the waste recycling industry in Colombia provides employment for 1 to 2 percent of the labor force (Pacheco 1992). According to Kathmandu Metropolitan City (KMC), there are 30 to 35 groups of waste pickers operating with a total of more than one hundred persons at Teku Transfer Station and the Bagmati River dumping site.

\section{Population Composition in Kabadi Shop}

The composition of people working in this business is changing since last 10 years. Kabadi shops were first started by the people form India. Before in this business only Indian, Terai or Kathmandu people were involved but now people from other part of the country are also working in this business. Especially people from lower cast are involved in this business i.e. Kami, Sharki etc. Nepali citizen working in this business are now increasing. From field study, in past $47 \%$ was Indian national but now it is only $33 \%$.

\section{CONCLUSIONS}

This study provided status of scrap waste and defined the composition of scrap waste. Generally glass waste are reused, likewise paper and plastics are mostly recycled. There is increasing number of Nepali people involving in this business and should be acknowledge for their contribution to the waste management. Some of scrap waste are processed by the scrap waste dealer for their convenience to transport the material. More than fifty percent of waste are recycled or reused within Nepal. 41 percent of scrap waste is collected through door to door collection system which gives its significance and should be promoted.

\section{ACKNOWLEDGEMENTS}

The authors are greatly thankful to the scrap dealers and contractor for their cooperation during study period. The authors are also thankful to Kathmandu University for their support to carryout the study. Thanks to Solid Waste and Resource Management and Mobilization Center and District Development Committee of Kathmandu and Lalitpur Districts for providing necessary information and guidance.

\section{REFERENCES}

1. Asian Institute of Technology - AIT, 2004. Municipal Solid Waste Management in Asia, Asian Regional Research Program on Environmental Technology (ARRPET), AIT, Thailand. ISBN:974-417-258-1.

2. Beed N., And Bloom, E., (1995). The Economics of Municipal Solid Waste. The World Bank Research Observer.

3. Beukering, P.J.H. van, and Badrinath, G.D. 1995. Challenges for the recycling industry in Nepal. Warmer Bulletin. No.46. p.6-7.

4. Blight G. E. and Mbande C. M. 1998. Waste Management in Developing Countries. In The Kriton Curi International Symposium on Environmental Management in the Mediterranean Region, Proceedings, Volume 1, Pages 373-383, Editor Prof. Dr. Günay Kocasoy, Istanbul, 1998. 
5. Cointreau S., Gunnerson, C., Huls, J., And Seldman, N., 1984. Recycling from Municipal Refuse: World Bank Technical Paper No. 30. The World Bank, Washington DC.

6. Devkota D. C., K. Watanabe, V. Dangol. 2004. Need for Alternative Approaches in Solid Waste Management - Case Study Kathmandu Valley. 30th WEDC International Conference: People-Centred Approaches to Water and Environmental Sanitation. Vientiane, Lao PDR.

7. Dhussa, A. K. and Varsney, A. K. 2000. Energy Recovery from Municipal Waste - Potential and Possibility, Bio Energy News, UNDP, Vol. 4, No. 1 pp $18-21$.

8. EPA 1996. Pick Up Savings: Adjusting Hauling Services While Reducing Waste.

9. Muller, L., 2002. Waste Indicators in South Africa: Journal for Sustainable Waste Management - Warmer Bulletin No. 82: P6.

10. Neogi S.K. and Mukherjee. S.K 2000. Recyclcling municipal solid waste. 26th WEDC Conference: Water Sanitation and Hygiene:Challnges of the millennium. Dhaka, Bangladesh.

11. Nippon Koei Co. Ltd; Yachiyo Engineering Co. Ltd. 2005. The Study on the Solid Waste Management for the Kathmandu Valley, Final Report (Clean Kathmandu Valley - CKV- Study)". Kathmandu: Ministry of Local Development, His Majesty's Government of Nepal; Japan international Cooperation Agency (JICA).

12. Pacheco, M. 1992. Recycling in Bogot: developing a culture for urban sustainability. Environment and Urbanization, Vol. 4, No. 2. P.74-79.

13. Pier Vellinga, Joyeeta Gupta and Frans Berkhout 1998. Managing a Material World. Kluwer Academic Publishers, Dordrecht p.229-239.

14. UN 2000. State of the Environment in Asia and the Pacific. United Nations Economic and Social Commission for Asia and Pacific and Asian Development Bank (ESCAP \& ADB), United Nations Publication, New York. ISBN:92-1-120019-9.

15. UNEP/ GRID-Arendal (March 2006); http://www.grida.no/

16. World Business Council for Sustainable Development (WBCSD), 2004. Sustainable Livelihoods, Case Studies. Available online: http://www.wbcsd.org/plugins/DocSearch/. 